AperTO - Archivio Istituzionale Open Access dell'Università di Torino

\title{
Clinical Management and Outcomes of Adrenal Hemorrhage Following Adrenal Vein Sampling in Primary Aldosteronism
}

\section{This is the author's manuscript}

Original Citation:

\section{Availability:}

This version is available http://hdl.handle.net/2318/1590661

since 2016-09-01T12:54:04Z

Published version:

DOI:10.1161/HYPERTENSIONAHA.115.06305

Terms of use:

Open Access

Anyone can freely access the full text of works made available as "Open Access". Works made available under a Creative Commons license can be used according to the terms and conditions of said license. Use of all other works requires consent of the right holder (author or publisher) if not exempted from copyright protection by the applicable law. 
2 in primary aldosteronism.

3 Silvia Monticone*, Fumitoshi Satoh*, Anna S. Dietz, Remi Goupil, Katharina Lang, Francesca

4 Pizzolo, Richard D. Gordon, Ryo Morimoto, Martin Reincke, Michael Stowasser**, Paolo 5 Mulatero**.

$6 \quad *$ and $* *$ equal contribution

\section{Affiliations}

Division of Internal Medicine and Hypertension (S.M., P.M.), Department of Medical Sciences, University of Torino, Torino, Italy; Division of Clinical Hypertension, Endocrinology \& Metabolism (F.S., R.M.), Tohoku University Graduate School of Medicine, Sendai, Japan; Endocrine Hypertension Research Centre (R.G., R.D.G., M.S.), University of Queensland School of Medicine, Greenslopes and Princess Alexandra Hospitals, Brisbane; Unit of Internal Medicine (F.P.), Department of Medicine, University of Verona, Verona, Italy; Department of Internal Medicine I (K.L.), University Hospital Wuerzburg, Wuerzburg, Germany; Medizinische Klinik und Poliklinik IV (A.S.D., M.R.), Ludwig-Maximilians-Universität, Munich, Germany.

Short title: Adrenal haemorrhage in primary aldosteronism

Abbreviations: PA: primary aldosteronism; EH: essential hypertension; AVS: adrenal vein sampling; APA: aldosterone producing adenoma; BAH: bilateral adrenal hyperplasia; AH: adrenal hemorrhage.

Word count: abstract 246 words, manuscript: 5799 words

Number of figures/tables: 1 figure, 2 tables

\section{Corresponding author and person to whom reprints should be addressed:}


1 Paolo Mulatero, Division of Internal Medicine and Hypertension, Department of Medical Sciences,

2 University of Torino.

3 Via Genova 3, 10126, Torino, Italy

4 Phone: +39-0116336959 Fax: +39-0116336031

5 paolo.mulatero@libero.it

6

7

8

9

10

11

12

13

14

15

16

17

18

19

20

21

22

23

24

25

26 


\section{Abstract}

Aldosterone-producing adenoma and bilateral adrenal hyperplasia account for more than $90 \%$ of all primary aldosteronism cases. Distinguishing between bilateral and unilateral disease is of fundamental importance because it allows targeted therapy. Adrenal vein sampling is the only reliable means to preoperatively differentiate between unilateral and bilateral subtypes. A very rare but serious complication of adrenal vein sampling is an adrenal haemorrhage. We retrospectively examined in detail 24 cases of adrenal haemorrhage during adrenal vein sampling in 6 different referral hypertension centers. Adrenal haemorrhage more often affected the right adrenal (n=18) than the left ( $n=5, P<0.001 ; 1$ bilateral). Median duration of experience of the radiologist in adrenal vein sampling at the time of adrenal haemorrhage was 5.0 years [0.6-7.8] and adrenal haemorrhage occurred with both highly experienced (>10 yrs) and less experienced radiologists. Of 9 patients who suffered adrenal haemorrhage in the gland contralateral to an aldosterone-producing adenoma and who underwent complete $(n=6)$ or partial $(n=3)$ unilateral adrenalectomy, only one required longterm corticosteroid replacement for adrenal insufficiency. No reduction in blood pressure or biochemical resolution of primary aldosteronism occurred in any of those patients who experienced adrenal haemorrhage in the gland ipsilateral to an aldosterone-producing adenoma $(n=6)$ or who had bilateral adrenal hyperplasia $(n=9)$. No patient required invasive treatments to control bleeding or blood transfusion. In conclusion, adrenal haemorrhage usually has a positive outcome causing either no or minor effects on adrenal function and adrenal vein sampling should remains the best approach to primary aldosteronism subtype differentiation.

Key words: primary aldosteronism, adrenal vein sampling, aldosterone-producing adenoma, bilateral adrenal hyperplasia, adrenal hemorrhage 
2 Studies both in vivo and in vitro have demonstrated that aldosterone plays a detrimental role on the

3 cardiovascular system and patients affected by primary aldosteronism (PA) have an increased rate of

4 cardio- and cerebro-vascular complications compared to essential hypertensives with a similar blood

5 pressure levels $(1,2)$. In light of these considerations, the early identification of PA is crucial to enable targeted treatment to reverse the excess of organ damage in affected patients. As detailed by the Endocrine Society (3) and by the Japanese Endocrine Society Guidelines (4), optimal management of PA patients is dependent on the differentiation between aldosterone-producing adenoma (APA) and bilateral adrenal hyperplasia (BAH), the two most common subtypes of sporadic PA. Adrenal CT scanning with contrast and fine cuts is recommended in all confirmed PA patients to rule out malignancy (aldosterone-producing adrenocortical carcinoma), but it is otherwise unreliable for subtype differentiation since it lacks both sensitivity and specificity. In particular, micro-adenomas ( $<1 \mathrm{~cm}$ in diameter) can be overlooked and it is not possible to distinguish between non-secreting incidentalomas and APAs by adrenal CT scanning alone $(3,5)$. Adrenal vein sampling (AVS) is a demanding procedure consisting of the selective cannulation of the adrenal veins to identify the source of aldosterone overproduction. It was first described in the 1960s as a technique to localize APAs preoperatively (6), but its inherent invasiveness, lack of standardized criteria for interpretation of the hormonal results and the reported high complication rates at that time were major factors in hindering its employment in the clinical management of PA. A complication of AVS is adrenal haemorrhage (AH), secondary to adrenal vein rupture or, less frequently, to dissection, infarction or thrombosis (7). Historically, complication rates ranged between $5 \%$ to $10 \%$ and were reportedly associated with complete and permanent destruction of the gland (8-10). More recent studies, however, report a substantially lower rate of complications of between 0.2 to $0.9 \%(7,11)$. In part, this is likely to be related to the advent of CT for the imaging of adrenal lesions and the consequent abandonment of the practice of retrograde adrenal venography which required injection of a relatively large amount of 
contrast under considerable pressure, and was associated with an increased risk of AH (7). Interestingly, a recent observational, retrospective, multicenter study demonstrated that the rate of adrenal vein rupture was not predicted by the method of cannulation, but rather by the experience of the radiologist, that is, the number of AVS performed by each radiologist (7).

Despite an impressive number of studies comparing the performances of imaging techniques and AVS in the subtype differentiation of PA (12), a systematic study on AH has never been performed and uncertainties in the clinical management of this complication still remain. The aim of this study was to describe the clinical presentation, management and outcome of $24 \mathrm{AH}$ cases, collected from 6 different tertiary referral hypertension centers, to help clinicians decide whether to use AVS in their PA patients.

\section{Materials and methods.}

\section{Patients selection.}

We retrospectively evaluated 24 cases of adrenal haemorrhage following AVS that occurred in 6 tertiary referral hypertension centers in Italy (Torino, 1994-01/2015, 427 AVS; Verona, 2009-2014, 31 AVS), Germany (Munich, 12/2009-01/2015, 255 AVS; Wuerzburg 12/2009-01/2015, 69 AVS), Japan (Sendai, 04/2007-12/2014, 640 AVS) and Australia (Brisbane, 1990-2014, 1446 AVS).

The control group comprised 1388 PA patients who underwent AVS in the different centres participating in the study, during a similar period of time as when the patients experienced AH during AVS (supplemental Table S1).

The diagnosis of PA was made according to the Endocrine Society and the Japanese Endocrine Society Guidelines $(3,4)$. Confirmatory testing and synacthen test were performed as detailed elsewhere (13-15). 
1 All patients included in the analysis gave written informed consent and approval from the local ethics committees was obtained for the use of these retrospective data. The study adhere to the principles of the Declaration of Helsinki and and to institutional guidelines. An expanded methods section is given in the supplemental file.

\section{Statistical analyses}

IBM SPSS Statistics 19 (SPSS INC, Chicago, IL) was used for statistical analyses. Data are presented as mean \pm standard error or median (25th-75th percentile). Data were analyzed with the KolmogorovSmirnov and Shapiro-Wilk tests to determine their distributions. Statistical significance between groups was calculated in normally distributed data by a Student $t$ test for independent samples and in not normally distributed data by the Kruskal-Wallis test, using Bonferroni corrections for multiple comparisons. The chi-square test of the Fisher exact test were used for qualitative variables. A probability value of less than 0.05 was considered statistically significant.

\section{Results.}

\section{General description of the cases.}

We retrospectively identified 24 cases of adrenal haemorrhage that occurred during AVS in 6 different referral hypertension centers in Italy, Germany, Japan and Australia. Clinical and biochemical characteristics (before and after AVS) of the patients included in the study are summarized in Tables 1 and 2.

In our series, $\mathrm{AH}$ was more frequent in the right adrenal $(n=18)$ than in the left $(n=5, P<0.001)$, and in one case AH was bilateral. In one case (MU-01) the patient was referred for super-selective adrenal vein sampling because of bilateral nodules at adrenal computed tomography (CT) scanning but lack of lateralization at previous, non-selective AVS. Haemorrhage occurred during the catheterization of side branches of the right adrenal vein. AVS showed highest aldosterone/cortisol-ratios in a vein draining the lateral limb of the right adrenal which bore an adenoma. In another case of right $\mathrm{AH}$ 
1 (BR-1), for the AVS procedure, gadolinium was used instead of iodinated contrast due to concerns

2 about contrast allergy.

3 CT scanning of a patient (TO-01) with right AH and left APA is shown is figure 1.

4 Patients experiencing AH were older than patients who underwent uncomplicated AVS procedures.

5 None of the other assessed clinical or biochemical and hormonal parameters were significantly

6 different between the $\mathrm{AH}$ and the controls (supplemental table 1). Of the 24 patients included in the study, two were taking aspirin $100 \mathrm{mg} /$ day (WU-01 and MU-03) one of whom was also under treatment with enoxaparin $0.4 \mathrm{mg}$ (MU-03) (of note the percentage of patients on aspirin was not significantly different from the percentage of total PA patients receiving aspirin treatment within the

Torino unit; data not shown); no other patients were receiving medications that are likely to have affected coagulation or platelet aggregation thereby facilitating the occurrence of $\mathrm{AH}$. In our series there were no significant comorbidities other than diabetes in one patient (BR-10) and polymyalgia rheumatica treated with steroids in another (MU-03).

According to AVS results, the final diagnosis was bilateral adrenal hyperplasia in 9 patients, left APA in 8 patients and right APA in 7 patients. In two patients (BR-7 and SE-03) the first AVS was not diagnostic: in BR-7 the right adrenal vein was not cannulated and in SE-03 the AVS was stopped after the occurrence of adrenal vein rupture. Repeated AVS revealed a final diagnosis of BAH in SE03 and left APA in BR-7.

The median duration of experience of the radiologist in AVS at the occurrence of the AH was 5.0 years $\left[0.6-7.8,25^{\text {th }}-75^{\text {th }}\right.$ percentile] and, at the time of $\mathrm{AH}, 33 \%(8 / 24)$ of the radiologists performed less than $10 \mathrm{AVS} /$ year, while 67\% (16/24) performed more than $10 \mathrm{AVS} /$ year.

In all but 2 patients, the occurrence of $\mathrm{AH}$ required hospitalization or a prolongation of hospital stay compared to non-complicated procedures for an average of $1.9 \pm 1.3$ days. Overall $54 \%(13 / 24)$ of the patients required the administration of a strong opioid (morphine, pethidine, piritramide, fentanyl) for efficient pain management, 8\% required the administration of a weak opioid (codeine, tramadol), while 38\% (9/24) required no analgesic medications. After the diagnosis of AH, adrenal CT was 
performed in 16 patients, one of whom also underwent NP-59 adrenal scintigraphy, to evaluate the residual activity of the affected adrenal gland. In 8 patients imaging was not performed. In our series none of the patients required invasive treatments to control bleeding or blood transfusion because of anaemia.

\section{Final diagnosis of unilateral PA, AH contralateral to the adenoma.}

Of the 15 patients displaying unilateral disease, AH occurred in the contralateral side to the adenoma in 9 cases. None of the 9 patients with $\mathrm{AH}$ contralateral to the side of lateralization showed BP reduction after the occurrence of the AH. Three of these 9 patients underwent nodulectomy and 6 underwent total laparoscopic adrenalectomy. In all patients who underwent total adrenalectomy and had AH contralateral to the adenoma, adrenal function was tested to rule out adrenal insufficiency. Plasma cortisol at 8:00 a.m. was within the normal range (5-25 mg/dL) in all patients; rapid synacthen test was normal in five of the six tested patients (normal values $>500 \mathrm{nmol} / \mathrm{L}, 18.1 \mathrm{mcg} / \mathrm{dL}$ ). In two patients (with right $\mathrm{AH}, \mathrm{BR}-01$ and BR-10) left adrenalectomy was performed under hydrocortisone cover. In the immediate post-operative period, patient BR-10 received ongoing treatment with dexamethasone while undergoing a short synacthen test (which showed a very blunted response from $<35$ to $83 \mathrm{nmol} / \mathrm{L}$ ) followed by a "long synacthen test" (0900h cortisol levels basally and daily for two days after commencement of intramuscular depot tetracosactrin, $1 \mathrm{mg} 12$ hourly). Because the latter demonstrated a definite (albeit modest) cortisol response (from $<35$ to 306 nom/L by day 1 and $271 \mathrm{nmol} / \mathrm{l}$ by day 2), dexamethasone was gradually withdrawn but an adrenal crisis occurred following subsequent shoulder surgery and the patient was therefore commenced (and remains) on cortisol and fludrocortisone supplementation. In patient BR-01 the test was performed 5 days after adrenalectomy and demonstrated a sub-normal response (from 303 to $484 \mathrm{nmol} / \mathrm{L}$ ) and he therefore remained on glucocorticoid supplementation with plans for repeat testing in six weeks' time. Adrenal function was also assessed in all patients who underwent nodulectomy (n=3) (in one case, WU-01 the tests were performed and reported as normal, but hormonal values were not available) and was found to be normal in each case (in BR-11 short synacthen test 1 month after adrenalectomy showed a 
partially blunted response after 60 minutes; the test was repeated 4 months later and showed an adequate response). In one patient (TO-01) NP-59 adrenal scintigraphy performed without dexamethasone suppression demonstrated a focus of tracer uptake by the right adrenal in agreement with residual right adrenal cortex function (Supplemental Figure S3): this patient had a normal synacthen test after nodulectomy. Of the three patients who underwent nodulectomy, two became normotensive without any anti-hypertensive medication and one displayed significant improvement of hypertension (normotensive on irbesartan $150 \mathrm{mg} /$ day, before adrenalectomy SBP $180 \mathrm{mmHg}$, DBP $100 \mathrm{mmHg}$ on three anti-hypertensive medications). Of the 6 patients who underwent total unilateral adrenalectomy, one displayed long-term adrenal insufficiency (BR-10) but BR-01, who demonstrated a blunted cortisol response to synacthen in the early post-operative period requires repeat testing to assess whether normal adrenal function has returned (adrenalectomy performed in March 2015). Four patients were cured of PA and hypertension, 1 displayed significant amelioration of blood pressure levels and biochemical cure of PA and 1 was operated only in March 2015 and has not been fully re-evaluated after the operation.

\section{Final diagnosis of unilateral PA, AH ipsilateral to the adenoma.}

Of the 15 patients displaying unilateral disease, AH occurred in the side of the adenoma in 6 cases. According to the historical reports indicating permanent adrenal dysfunction after $\mathrm{AH}$, we would have expected that $\mathrm{AH}$ in the side of the adenoma to have resulted in cure of PA without further treatment. However in our series, none of the patients displayed cure of PA or improvement of hypertension following $\mathrm{AH}$, and all patients therefore still required unilateral adrenalectomy. Consistently, aldosterone levels did not change significantly after the $\mathrm{AH}$ but before the adrenalectomy in the four out of six patients who had the hormone tested (Supplemental Table S2). The occurrence of the AH was confirmed in all cases by histology report, clearly showing presence of recent bleeding in both the tumor and the adjacent adrenal tissue. None of these patients had evidence of adrenal insufficiency, as expected. 
1 In a recent report, hypertension was improved in 14 of 40 patients with BAH who underwent

2 unilateral adrenalectomy (16). We analyzed the post-AVS parameters of the 9 BAH patients who experienced unilateral $\mathrm{AH}$. Of note, none of the patients displayed any degree of blood pressure reduction or amelioration of PA after unilateral AH. As expected, we did not detect signs or symptoms of adrenal insufficiency in these patients.

\section{Discussion.}

The diagnosis of PA is a three step process (screening, confirmation and subtype differentiation) and AVS is recognized by the Endocrine Society and Japanese Endocrine Society Guidelines $(3,4)$ as the gold standard test to distinguish between unilateral and bilateral disease. It is a demanding interventional procedure where the adrenal veins are accessed through a femoral vein approach and cannulated to identify the source of aldosterone overproduction. The left adrenal vein almost always drains into the left renal vein and it is therefore usually relatively easy to cannulate. On the contrary, the right adrenal vein is small, drains directly into the inferior vena cava and it is therefore more difficult to cannulate (17). Moreover, despite significant efforts towards standardization, AVS protocols and interpretation of hormone results vary widely across centers $(5,12)$.

Adrenal vein rupture and subsequent AH represent the most serious complication of AVS. Despite being now widely recognized that the prevalence of $\mathrm{AH}$ is not as high as suggested by historical reports, the clinical outcomes of this complication have never been systematically investigated and evidence on the subsequent optimal management is still lacking.

In this study we collected 24 cases of AH through 6 different referral hypertension centers in Italy, Germany, Japan and Australia and retrospectively investigated the clinical management and the outcomes in terms of hospital stay, need for medications/interventional procedure and the rate of complete and permanent destruction of the affected adrenals. Interestingly, as suggested by historical reports (9) we observed that $\mathrm{AH}$ occurred more frequently in the right adrenal vein suggesting that the anatomy, unfavorable for cannulation, can at least partially account for this difference. In addition, 
the higher number of attempts necessary to cannulate the right adrenal vein may have contributed to the higher rate of AH. Overall, abdominal pain was the most common symptom associated with the occurrence of $\mathrm{AH}$ and required treatment with strong opioids in the majority of the patients. Follow up imaging was performed in most patients, mainly by CT scanning. Only in one case was functional evaluation by adrenal scintiscan performed. In this patient the uptake of the tracer in the adrenal containing the AH demonstrated that the complication did not result in loss of functional activity of the gland.

A recent observational retrospective multicenter study (7) showed that the rate of adrenal vein rupture was inversely correlated with the number of procedures performed by each radiologist and directly with the number of AVS procedures performed per center. However, in our series AH occurred with both experienced radiologists ( $>5$ years of experience and $>10$ procedures/year) and inexperienced ones, consistent with experience of the operator being not the only important factor associated with the occurrence of $\mathrm{AH}$.

It should be noted that in two patients with AH, AVS was successfully and uneventfully repeated without complication, showing that a previous $\mathrm{AH}$ does not necessary exclude the feasibility of a subsequent AVS.

The most important finding of this study is represented by the outcome data regarding the residual function of the affected adrenal. In our series of $24 \mathrm{AH}$ only one patient, after removal of the adrenal contralateral to the $\mathrm{AH}$, displayed signs and symptoms of adrenal insufficiency, requiring long-term therapy with replacement doses of hydrocortisone. In another case operated in March 2015 the synacthen test was slightly suboptimal and the patient will be subsequently re-evaluated by repeat testing. These findings show that the functional activity of the adrenals after the haemorrhage is in most cases not markedly impaired by this complication. In agreement with these findings we did not observe a blood pressure reduction after the AH when the event involved the adrenal bearing the APA or in BAH patients. 
1 In clinical practice, when the AH involves the contralateral adrenal to an APA the clinician may be concerned about the residual adrenal function of the affected adrenal gland and hence whether corticoisteroid replacement will be required peri-operatively and long-term following unilateral adrenalectomy. One option is to perform an adrenal-sparing nodulectomy to save part of the functioning cortex surrounding the APA. However, this surgical option has the potential disadvantage of PA persisting if the removed nodule was not the sole source of excessive aldosterone production (18). In fact, aldosterone production outside the main nodule of the removed adrenal was observed in immunohistochemistry studies using specific antibodies for CYP11B2 $(19,20)$. To overcome this disadvantage, super selective segmental adrenal vein branches AVS would be required (21). However, this technique is highly demanding and is only available in few specialized centres (22). In addition to performing short synacthen testing post-operatively, pre-operative testing for residual adrenal function in the gland bearing the $\mathrm{AH}$ by performing adrenal scintiscan using ${ }^{131} \mathrm{I}-\mathrm{nor}$ cholesterol (NP59) without dexamethasone suppression could be considered. This procedure has been suggested previously (23) and successfully undertaken in one of our patients (TO-01) before contralateral adrenalectomy to the AH. Furthermore, the identification of the anatomy of right adrenal vein by contrast-enhanced multidetector CT before AVS may be helpful to shorten the time required for AVS performance, thereby reducing the AH risk $(11,24)$. Finally, in some selected cases in which the clinical, radiological and biochemical information point strongly towards unilateral APA, a case for avoiding AVS could be made $(11,24-28)$.

The main limitation of the present study is the retrospective nature of data collection; therefore the evaluation of patients’ outcome after the adrenal haemorrhage was not standardized.

In conclusion, to the best of our knowledge this represents the first study undertaken primarily to explore the management and the outcomes of AH occurring during AVS. AH, despite being the most dreaded complication of AVS, usually has a positive outcome causing minor or no permanent effects 
on adrenal function and should not discourage clinicians from using AVS to correctly diagnose the PA subtype.

(1)

\section{Perspectives}

A wealth of studies clearly demonstrated that PA is the most frequent cause of secondary hypertension. AVS is the only reliable way of differentiating unilateral PA forms that benefit from adrenalectomy from bilateral forms that are treated pharmacologically. AVS is currently performed in few referral centres: one of the obstacles to the wide acceptance of this technique is the invasive nature of the procedure that in some cases is complicated by $\mathrm{AH}$. In the present study this rare complication usually had a positive outcome in terms of adrenal function. Therefore, AVS should be offered to all PA patients that are considered for unilateral adrenalectomy,

Source of Funding: This study was funded by a grant from MIUR 2013 (ex 60\%, Ministry of Instruction, University and Research, Italy, to P.M.) and by a grant from MIUR 2014 (ex-60\%, Ministry of Instruction, University and Research, Italy, to S.M.). The German Conn Registry-Else Kröner-Fresenius-Hyperaldosteronismus Registry is supported by a grant from Else KrönerFresenius-Stiftung to MR (2013_A182). R.G. received salary support from the Fonds de recherche du Québec en santé and the Société québécoise d’hypertension artérielle.

Disclosure summary: the authors have nothing to disclose

\section{References}

1. Mulatero P, Monticone S, Bertello C, Viola A, Tizzani D, Iannaccone A, Crudo V, Burrello J, Milan A, Rabbia F, Veglio F. Long-Term Cardio- and Cerebrovascular Events in Patients With Primary Aldosteronism. J Clin Endocrinol Metab. 2013;48:4826-4833.

2. Savard S, Amar L, Plouin PF, Steichen O. Cardiovascular complications associated with primary aldosteronism: a controlled cross-sectional study. Hypertension. 2013;62:331-336. 
3. Funder JW, Carey RM, Fardella C, Gomez-Sanchez CE, Mantero F, Stowasser M, Young WF Jr, Montori VM; Endocrine Society. Case detection, diagnosis, and treatment of patients with primary aldosteronism: an Endocrine Society Clinical Practice Guideline. J Clin Endocrinol Metab. 2008;93:3266-3281.

4. Nishikawa T, Omura M, Satoh F, Shibata H, Takahashi K, Tamura N, Tanabe A; Task Force Committee on Primary Aldosteronism, The Japan Endocrine Society. Guidelines for the diagnosis and treatment of primary aldosteronism—-the Japan Endocrine Society. Endocr J. 2011;58:711-721.

5. Monticone S, Viola A, Rossato D, Veglio F, Reincke M, Gomez-Sanchez C, Mulatero P. Adrenal vein sampling in primary aldosteronism: towards a standardised protocol. Lancet Diabetes Endocrinol. 2015;3:296-303.

6. Melby JC, Spark RF, Dale SL, Egdahl RH, Kahn PC. Diagnosis and localization of aldosterone-producing adenomas by adrenal-vein cateterization. $N$ Engl $J$ Med. $1967 ; 277: 1050-1056$.

7. Rossi GP, Barisa M, Allolio B, et al. The Adrenal Vein Sampling International Study (AVIS) for identifying the major subtypes of primary aldosteronism. J Clin Endocrinol Metab. 2012;97:1606-1614.

8. Bookstein JJ. The roles of angiography in adrenal disease. In: Abram's angiography. 3rd ed. Boston, Mass: Little, Brown, 1983;1395-1424.

9. Walters NA, Thomson KR. Urogenital venography. In: Rifkin MD, Thomson K, Rickards D, Jones S, eds. Practical interventional uroradiology. Edinburgh, Scotland: Edward Arnold, 1993; chap 11.

10. Gross MD, Falke THM, Shapiro B, Sandler MP. Adrenal glands. In: Endocrine imaging. Norwalk, Conn: Appleton \& Lange, 1992:271;349.

11. Daunt N. Adrenal vein sampling: how to make it quick, easy, and successful. Radiographics. 2005;25:S143-158. 
12. Kempers MJ, Lenders JW, van Outheusden L, van der Wilt GJ, Schultze Kool LJ, Hermus AR, Deinum J. Systematic review: diagnostic procedures to differentiate unilateral from bilateral adrenal abnormality in primary aldosteronism. Ann Intern Med. 2009;151:329-337.

13. Monticone S, Satoh F, Viola A, et al. Aldosterone suppression on contralateral adrenal during adrenal vein sampling does not predict blood pressure response after adrenalectomy. $J$ Clin Endocrinol Metab. 2014; 99:4158-4166.

14. Wolley MJ, Gordon RD, Ahmed A, Stowasser M. Does contralateral suppression at adrenal venous sampling predict outcome following unilateral adrenalectomy for primary aldosteronism? A retrospective study. J Clin Endocrinol Metab. 2015;100:1477-1484.

15. Husebye ES, Allolio B, Arlt W, Badenhoop K, Bensing S, Betterle C, Falorni A, Gan EH, Hulting AL, Kasperlik-Zaluska A, Kämpe O, Løvås K, Meyer G, Pearce SH. Consensus statement on the diagnosis, treatment and follow-up of patients with primary adrenal insufficiency. J Intern Med. 2014; 275:104-115.

16. Sukor N, Gordon RD, Ku YK, Jones M, Stowasser M. Role of unilateral adrenalectomy in bilateral primary aldosteronism: a 22-year single center experience. J Clin Endocrinol Metab. 2009;94:2437-2445

17. Young WF, Stanson AW. What are the keys to successful adrenal venous sampling (AVS) in patients with primary aldosteronism? Clin Endocrinol (Oxf). 2009;70:14-17.

18. Ishidoya S, Ito A, Sakai K, Satoh M, Chiba Y, Sato F, Arai Y. Laparoscopic partial versus total adrenalectomy for aldosterone producing adenoma. J Urol. 2005;174:40-43.

19. Dekkers T, ter Meer M, Lenders JW, Hermus AR, Schultze Kool L, Langenhuijsen JF, Nishimoto K, Ogishima T, Mukai K, Azizan EA, Tops B, Deinum J, Küsters B. Adrenal nodularity and somatic mutations in primary aldosteronism: one node is the culprit? J Clin Endocrinol Metab. 2014;99:E1341-1351. 
20. Monticone S, Castellano I, Versace K, Lucatello B, Veglio F, Gomez-Sanchez CE, Williams TA, Mulatero P. Immunohistochemical, genetic and clinical characterization of sporadic aldosterone-producing adenomas. Mol Cell Endocrinol. 2015; 411:146-154.

21. Satani N, Ota H, Seiji K, Morimoto R, Kudo M, Iwakura Y, Ono Y, Nezu M, Omata K, Ito S, Satoh F, Takase K Segmental adrenal venous sampling for localization of intra-adrenal aldosterone secretion. Radiology. 2015:142159. [Epub ahead of print]. PMID: 26147784.

22. Satoh F, Morimoto R, Seiji K, et al. Is there a role for segmental adrenal venous sampling and adrenal sparing surgery in patients with primary aldosteronism? Eur J Endocrinol. 2015;173:465-477.

23. Gianchandani RY, Quin GA, Grekin RJ, Gross MD, Sisson JC, Thompson NW, Shapiro B. Simultaneous scintigraphic depiction of aldosteronoma and adrenal infarction. J Nucl Med. 1996;37:852-854.

24. Rossi GP, Auchus RJ, Brown M, Lenders JW, Naruse M, Plouin PF, Satoh F, Young WF Jr. An expert consensus statement on use of adrenal vein sampling for the subtyping of primary aldosteronism. Hypertension 2014;63:151-160.

25. Satoh F, Morimoto R, Ono Y, et al. Measurement of peripheral plasma 18-oxocortisol can discriminate unilateral adenoma from bilateral diseases in patients with primary aldosteronism. Hypertension 2015;65:1096-1102.

26. Riester A, Fischer E, Degenhart C, Reiser MF, Bidlingmaier M, Beuschlein F, Reincke M, Quinkler M. Age below 40 or a recently proposed clinical prediction score cannot bypass adrenal venous sampling in primary aldosteronism. J Clin Endocrinol Metab. 2014;99:E10351039.

27. Lim V, Guo Q, Grant CS, Thompson GB, Richards ML, Farley DR, Young WF Jr. Accuracy of adrenal imaging and adrenal venous sampling in predicting surgical cure of primary aldosteronism. J Clin Endocrinol Metab. 2014;99:2712-2719. 
28. Mulatero P, di Cella SM, Monticone S, Schiavone D, Manzo M, Mengozzi G, Rabbia F, Terzolo M, Gomez-Sanchez EP, Gomez-Sanchez CE, Veglio F. 18-hydroxycorticosterone, 18-hydroxycortisol, and 18-oxocortisol in the diagnosis of primary aldosteronism and its subtypes. J Clin Endocrinol Metab. 2012;97:881-889.

\section{Novelty and Significance:}

What Is New

- Adrenal haemorrhage (AH) following AVS in primary aldosteronism is a rare event and is more frequent in the right adrenal than in the left and in older patients.

- None of the patients affected by AH on the side of the adenoma displayed cure of PA or improvement of hypertension following $\mathrm{AH}$.

- The occurrence of AH required hospitalization or a prolongation of hospitalization compared to non-complicated procedures and required treatment with strong opioid for efficient pain management in the majority of patients.

- Only one patient, after removal of the adrenal contralateral to the $\mathrm{AH}$, displayed signs and symptoms of adrenal insufficiency, requiring long-term therapy with replacement doses of hydrocortisone.

\section{What Is Relevant}

- AH usually has a positive outcome causing either none or only minor permanent effects on adrenal function. Therefore, AVS should remain the favoured approach to PA subtype differentiation. 
2 Adrenal haemorrhage is a rare complication of adrenal vein sampling for subtype diagnosis of

3 primary aldosteronism and usually is followed by a favourable outcome in term of adrenal function.

4

$5 \quad$ Legend to figures.

$6 \quad$ Figure 1. CT scan just after AVS in patient TO-01.

7 Panel A: left adrenal gland with a discrete $1 \mathrm{~cm}$-diameter nodule at the lateral gland limb (arrow).

8 Panel B: right supra-renal space is almost completely filled by an oval hematoma (arrow-head).

9 Two different cuts are shown because adrenal glands were situated in on different CT planes. 


\begin{tabular}{|c|c|c|c|c|c|c|c|}
\hline Patients & $\begin{array}{c}\text { Age at AVS } \\
\text { (years) }\end{array}$ & Sex & $\begin{array}{c}\text { SBP/DBP } \\
\text { (number of } \\
\text { drugs) } \\
\text { before AVS }\end{array}$ & $\begin{array}{l}\text { Experience of the } \\
\text { radiologist in AVS at the } \\
\text { time of the AH (years) }\end{array}$ & Year of the AH & Side of AH & $\begin{array}{c}\text { Diagnosis } \\
\text { at AVS }\end{array}$ \\
\hline BR-01 & 41 & $\mathrm{M}$ & 143/88 (3) & 8 & 2013 & Right & Left APA \\
\hline BR-02 & 41 & $\mathrm{M}$ & $180 / 110(4)$ & 3 & 1992 & Right & BAH \\
\hline BR-03 & 45 & $\mathrm{M}$ & 155/105 (3) & $<1$ & 1992 & Right & Right APA \\
\hline BR-04 & 69 & $\mathrm{M}$ & 154/84 (1) & $<1$ & 1994 & Right & BAH \\
\hline BR-05 & 65 & $\mathrm{M}$ & $136 / 80(4)$ & $<1$ & 1992 & Right & BAH \\
\hline BR-06 & 58 & $\mathrm{~F}$ & $110 / 80(2)$ & $<1$ & 1995 & Bilateral & $\mathrm{BAH}$ \\
\hline BR-07 & 53 & $\mathrm{M}$ & $154 / 98(3)$ & 1 & 1995 & Left & N.D.* \\
\hline BR-08 & 60 & $\mathrm{~F}$ & 162/84 (3) & 2 & 1997 & Left & Left APA \\
\hline BR-09 & 58 & $\mathrm{~F}$ & $141 / 64(2)$ & 5 & 1999 & Right & BAH \\
\hline BR-10 & 67 & $\mathrm{M}$ & $180 / 94$ (3) & 6 & 2000 & Right & Left APA \\
\hline BR-11 & 68 & $\mathrm{M}$ & $140 / 90(1)$ & 18 & 2013 & Right & Left APA \\
\hline BR-12 & 51 & $\mathrm{M}$ & $155 / 80(0)$ & 15 & 2010 & Left & Right APA \\
\hline MU-01 & 35 & $\mathrm{~F}$ & $130 / 85$ (1) & 5 & 2014 & Right & Right APA \\
\hline MU-02 & 62 & $\mathrm{~F}$ & $184 / 83(1)$ & $<1$ & 2014 & Right & Right APA \\
\hline MU-03 & 76 & $\mathrm{M}$ & $170 / 80(3)$ & $<1$ & 2014 & Right & $\mathrm{BAH}$ \\
\hline MU-04 & 55 & $\mathrm{M}$ & $160 / 103(2)$ & 5 & 2012 & Right & Right APA \\
\hline WU-01 & 52 & $\mathrm{M}$ & $180 / 100$ (3) & 7 & 2000 & Right & Left APA \\
\hline SE-01 & 63 & $\mathrm{~F}$ & 155/87 (1) & 8 & 2008 & Right & Left APA \\
\hline SE-02 & 66 & $\mathrm{M}$ & $161 / 86(2)$ & 10 & 2010 & Left & Right APA \\
\hline SE-03 & 55 & $\mathrm{~F}$ & $126 / 79(4)$ & 7 & 2009 & Right & N.D. ${ }^{\S}$ \\
\hline SE-04 & 62 & $\mathrm{M}$ & $140 / 83(2)$ & 7 & 2007 & Left & Right APA \\
\hline SE-05 & 71 & $\mathrm{M}$ & 158/90 (1) & 4 & 2008 & Right & $\mathrm{BAH}$ \\
\hline TO-01 & 55 & $\mathrm{M}$ & $180 / 120(2)$ & 15 & 2012 & Right & Left APA \\
\hline VE-01 & 49 & $\mathrm{M}$ & $130 / 90(2)$ & 2 & 2014 & Right & BAH \\
\hline All & $57 \pm 11$ & - & $153 / 89(2)$ & $5.0[0.6-7.8]$ & & & \\
\hline
\end{tabular}

Table 1. Clinical parameters of patients with adrenal haemorrhage

* The AVS was repeated and then lateralized to the left; § The AVS was repeated and showed bilateral disease

SBP = systolic blood pressure; DBP = diastolic blood pressure; AH = adrenal haemorrhage; $\mathrm{CT}=$ computed tomography; N.D. = not diagnostic; AVS = adrenal vein sampling . 


\begin{tabular}{|c|c|c|c|c|c|c|}
\hline Patients & $\begin{array}{c}\text { Hospitalization } \\
\text { requirement (days) }\end{array}$ & Drugs for pain control & $\begin{array}{l}\text { Follow up } \\
\text { imaging }\end{array}$ & Adrenalectomy & $\begin{array}{l}\text { Same side/ } \\
\text { CL side }\end{array}$ & $\begin{array}{l}\text { SBP/DBP (no. } \\
\text { classes of drugs) } \\
\text { after AVS/ADX }\end{array}$ \\
\hline BR-01 & Yes (1) & Morphine s/c, paracetamol & CT scan & Yes & CL side & $182 / 116(3)$ \\
\hline BR-02 & Yes (2) & Pethidine, paracetamol & CT scan & No & N.A. & $160 / 80(4)$ \\
\hline BR-03 & Yes (3) & Pethidine, omnopon & CT scan & Yes & Same side & $156 / 110(1)$ \\
\hline BR-04 & Yes (1) & Pethidine & CT scan & No & N.A. & $160 / 80(1)$ \\
\hline BR-05 & Yes (2) & Morphine s/c, paracetamol & CT scan & No & N.A. & $192 / 96(5)$ \\
\hline BR-06 & No & Pethidine, paracetamol & None & No & N.A. & $130 / 68(2)$ \\
\hline BR-07 & No & None & None* & Yes & Same side & $164 / 88(2)$ \\
\hline BR-08 & Yes (1) & Pethidine, paracetamol & CT scan & Yes & Same side & $124 / 84(0)$ \\
\hline BR-09 & Yes (1) & Pethidine, paracetamol & CT scan & No & N.A. & $157 / 94(3)$ \\
\hline BR-10 & Yes (5) & Codeine, paracetamol & CT scan & Yes & CL side & $134 / 78(0)$ \\
\hline BR-11 & Yes (2) & Paracetamol, pethidine & CT scan & $\begin{array}{c}\text { No } \\
\text { (nodulectomy) }\end{array}$ & CL side & $140 / 80(0)$ \\
\hline BR-12 & Yes (3) & Paracetamol, pethidine & CT scan & Yes & CL side & $128 / 85(0)$ \\
\hline MU-01 & Yes (1) & Metamizol & None & $\begin{array}{c}\text { No } \\
\text { (nodulectomy) }\end{array}$ & Same side & $113 / 76(0)$ \\
\hline MU-02 & Yes (1) & None & None & Yes & Same side & $130 / 85(0)$ \\
\hline MU-03 & Yes (3) & Paracetamol & CT scan & No & N.A. & $145 / 65(3)$ \\
\hline MU-04 & Yes (3) & Piritramid & CT scan & Yes & Same side & $152 / 96(4)$ \\
\hline WU-01 & Yes (4) & Phetidine fentanyl & CT scan & $\begin{array}{c}\text { No } \\
\text { (nodulectomy) }\end{array}$ & CL side & $140 / 85(0)$ \\
\hline SE-01 & Yes (1) & None & None & Yes & CL side & $127 / 78(0)$ \\
\hline SE-02 & Yes (1) & None & None & Yes & CL side & $122 / 79(0)$ \\
\hline SE-03 & Yes (1) & None & None & No & N.A. & $117 / 70(3)$ \\
\hline SE-04 & Yes (1) & None & None & Yes & CL side & $126 / 82(1)$ \\
\hline SE-05 & Yes (1) & None & CT scan & No & N.A. & $120 / 68(2)$ \\
\hline TO-01 & Yes (3) & Morphine paracetamol & CT scan & $\begin{array}{c}\text { No } \\
\text { (nodulectomy) }\end{array}$ & CL side & $135 / 85(0)$ \\
\hline VE-01 & Yes (4) & Tramadol & $\begin{array}{l}\text { CT and Scinti } \\
\text { scan }\end{array}$ & No & N.A. & $120 / 80(1)$ \\
\hline All & $1.9 \pm 1.3$ & & & & & \\
\hline
\end{tabular}




\section{Table 2. Outcome parameters after adrenal haemorrhage.}

*Minor asymptomatic extravasation of contrast was seen at the time of AVS and further imaging was not considered clinically indicated.

$\mathrm{SBP}=$ systolic blood pressure; $\mathrm{DBP}=$ diastolic blood pressure; $\mathrm{CT}$ = computed tomography; N.A. = not applicable; AVS = adrenal vein sampling; ADX = adrenalectomy. 